\title{
On the Efficacy of Low Level Systems of Irrigation on Sloping Lands of Azerbaijan
}

\author{
Rae ZH Aliyev* \\ Institute of Erosion and Irrigation NAS of Azerbaijan, Baku
}

Submission: October 30, 2017; Published: November 27, 2017

*Corresponding author: Rae ZH Aliyev, Institute of Erosion and Irrigation NAS of Azerbaijan, Baku, Email: zakirakademik@mail.ru

\begin{abstract} applicable where other irrigation methods use is impossible or ineffective:

i. In difficult terrain and large lot slope (up to 45 degrees or more);

ii. In areas with prolonged drought and strong winds;

iii. water resources in local with a relatively limited amount of water;

iv. on soils with low power and very low or high Hygroscopicity;

v. On soils prone to salinization;

vi. When used for irrigation water with high content of water-soluble salts, etc.
\end{abstract}

Study of the world experience and results of long-term experiments with drip irrigation systems in different climatic and soil conditions shows that the establishment of irrigation systems of this type are efficiently and economically advantageous irrigation of different perennials, vegetable, row and industrial crops, ornamental plantings, nurseries etc. drip irrigation has almost universal application, in particular, it is

Conclusion: In conclusion, it should be noted that all of the above types of mikrodozhdevalnoj systems: (IDAD, KTMD, DMD and MACS) can be recommended for use in wet areas naturally is not enough mountain and Foothill regions of Azerbaijan for cultivation fruit, vines, cereals, fodder and other agricultural crops.

Keywords: Duration; Drought; Wind spa; Local moistening; Loss and Drip irrigation

\section{Introduction}

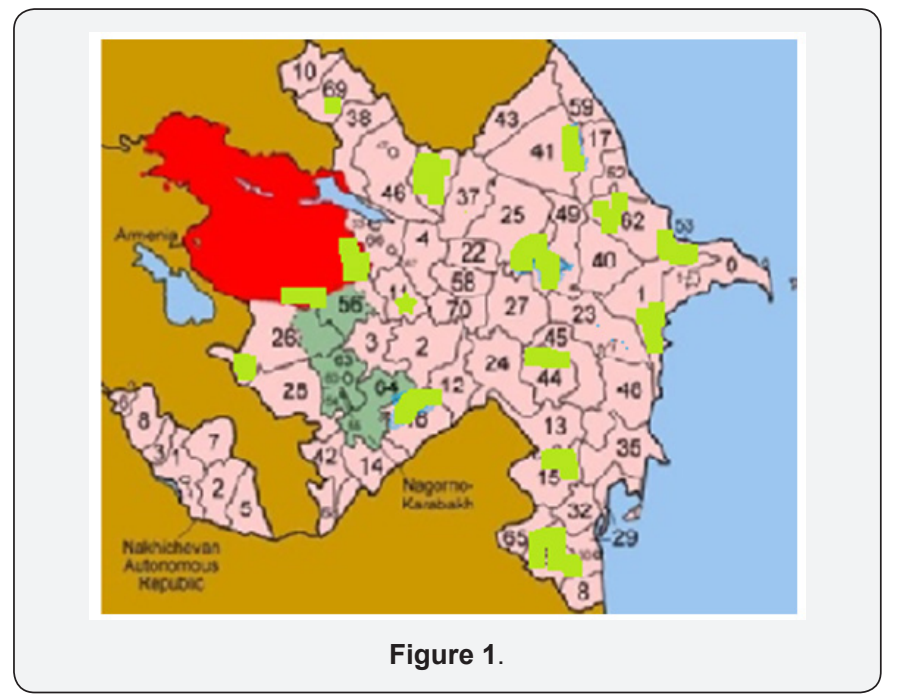

The basis for intensification of agriculture in the mountainous and Piedmont areas of the Republic are based mainly with the development of horticulture and viticulture in these regions is mining and irrigated agriculture (Figure 1). While here, from among the technology intensity of irrigation is used extensively drip irrigation systems. Note that in drip irrigation technology principle of continuous supply of water plants in accordance with the progress of water consumption, taking into account the possibility of technical means and the nature of soil moisture. This is a daily compensation water loss through evaporation and support optimum humidity in a given circuit soil moisture.

Moves Research

Under drip irrigation water use efficiency is $85-95 \%$. Drip irrigation provides a high yield per unit volume of water consumption. Under this irrigation the soil supported the most favorable air and nutrient regime for plant development. Thanks to the productivity of all cultures compared to conventional sprinkler systems increased by $40-60 \%$ and more. Especially the significant increase in yield is observed under irrigation of vegetable and melon crops. Due to the fact that under drip irrigation fertilizers and pesticides are made locally in small quantities and in the desired time frame, good absorption and achieved great savings in them. Drip irrigation technology includes water supply mode in accordance with water consumption culture. 
Water supply mode depends on the rules of the dates and duration of irrigation for irrigation period, the zone, flow, hydration number of drips and location schemes of water-physical properties of the soil. While very effective is the use of drip irrigation system in intensive technologies of cultivation of agricultural and ornamental plants, as well as the gardens when the State of the plants depend to a large extent on the accuracy maintain humidity conditions and diet. Drip irrigation is only a limited part of the soil surface without surface run-off or water filtration in the deeper layers of the soil. Drip irrigation allows you to maintain the same humidity root living layer during the entire growing period at an optimum level without significant variations, characteristic for other methods of irrigation. When the soil is carried out through the capillary hydration.

This saved the optimum soil water-physical properties in the root zone of plants (particularly in the critical phases of their development) and eliminates moisture loss due to surface run-off and infiltration in depth. It should be noted that this effect is more pronounced in arid climates, but also in the more humid regions of drip irrigation can substantially improve the qualitative indices of cultivated products. In fact, drip irrigation system as well as sprinkling system is stationary and allows you to fully automate the entire process of irrigation and power plants, which in turn leads to significant savings in labor costs. A well-designed system allows you to achieve the maximum of a uniform distribution of irrigation water and nutrients throughout the site, providing a standard development of plants and their dates of ripening, which facilitates harvesting and reduces its losses and a number of other indicators of agricultural production It should be noted that under drip irrigation water is supplied in the form of individual drops of diameter 1-2 mm or spray directly to the local area of the field and not pereraspredeljajas, hydrate the soil, mainly using capillary forces.

\section{Research Objectives}

Study of climatic and agronomic factors defining the types of irrigation technology under consideration do not in and of itself, but as an integral part of the technology of cropping. The effectiveness of this technology is determined by climatic and agronomic factors. In doing so, it should be noted that inadequate accounting for these factors can lead to undesirable effects such as surface runoff and deep filtration. In order to make the process of irrigation more environmentally perfect, you must select the best irrigation technology, which would ensure the best combination of artificial and natural precipitation and maximum use of the latter. A large number of options for Agro-Hydrology, climatic conditions, characteristics of the possible precipitation make assessment of irrigation technology very difficult. Output parameters to calculate the intensity and duration of rainfall and irrigation intensity of jevakotranspiracii.

Daily water supply is determined in accordance with the amount of evaporation from water surface and shall be calculated by the following formula [1]:

$$
(\mathrm{m})_{\text {SUT }}=10\left(\mathrm{E}_{\text {vers.h }}\right)(\mathrm{K}) \text { PL. }
$$

where, $(\mathrm{E})_{\text {exec }}$-evaporation over the previous 24 hours, mm;

(h) -Precipitation, mm; (h) -utilization of rainfall;

$(\mathrm{K})_{\mathrm{PL}}$--moisture ratio square.

Coefficient of moisture square. Determined from the expression [2]:

$$
K_{n \pi}=\frac{S * n}{10000}
$$

Where, S-area humidification of one plant, m; (n)-quantity of irrigation Engineering (DRIPs) on 1 ha;

Duration of supply is determined by the formula:

$$
t_{c y m}=\frac{1000 * . n c y m}{q * n}
$$

or

$t_{c y m}=\frac{\left(E_{u c n}-K h\right) S}{q}$

where, $t_{\text {suT }^{-}}$the daily duration of work systems of irrigation, low-intensity per hour;

(m) ${ }_{\text {SUT }^{*}}$-daily water supply, taking into account, bearing in mind the decision toPL., $\mathrm{m} / \mathrm{ha}$;

q-irrigation technology consumption (drips or sprinklers), l/h;

(n)-quantity of irrigation technology on 1 ha.

In formulas (3) and (4) function to (h) has significant influence to determine the technological process of irrigation;

To (h) -expresses productively used.

\section{K-coefficient}

The use of precipitation is functionally dependent on rainfall, soil type, slope, length of rain starting soil moisture and surface condition of the soil. Productively used precipitation characterized by utilization of rainfall. This part of precipitation is taken into account when calculating the irrigation norms and is its integral part. Taking into attention the $\mathrm{BH}$ Aliyev techniques [3] the numerical value of the coefficient used rainfall should is determined from the expression:

$$
\mathrm{K}=\frac{\Delta \mathrm{h}}{\mathrm{H}}
$$

where $\Delta(\mathrm{h})$-productively used precipitation, $\mathrm{mm}$; (h) -precipitation, mm. Productively used precipitation are determined by the water balance method:

$$
\text { (I) }
$$

$$
\begin{aligned}
& \Delta(h)=h_{k}-(h)_{n}= \sum(E)_{(i)} \\
&(i)=1
\end{aligned}
$$

where, $\mathrm{h}_{\mathrm{k}}$ - supply of moisture in the soil after a rain, $\mathrm{mm}$; $\Sigma(\mathrm{E})_{(i)}-$ the sum of evaporation from water surface covered for $\mathrm{i}=1$ period. 
The value of $\Delta(\mathrm{h})$ can be considered known as humidity with regular irrigation is maintained at a constant level. In examining the technological process of watering, you must know the occurrence of groundwater. Results if the ground water table at closer to korneobitaemomu soil layer, the daily water supply should be determined by the following formula [4]:

$$
(\mathrm{m}) \mathrm{d}=10 \mathrm{k}_{\mathrm{PL}}\left[\mathrm{e}_{\text {exec }}(1 \mathrm{~kg})-\mathrm{Kh}\right]
$$

Where to ${ }_{g}$-coefficient of groundwater, water-physical properties of the soil and the depth distribution of root system of plants. We offer two ways to process crop irrigation. The first method is based on the traditional method. According to this method when there is no rain daily soil moisture reserves become recharged until the desired size in accordance with the daily evaporation in the previous day. It uses the testimony of SGI isparometra-3000. At the beginning of the irrigation season and each time after rain measured initial soil moisture in any sufficiently precise method.

The second method is also based on the condition of daily filling was ground to desired values according to the preceding evaporation day the SGI isparometra indicators-3000. Here the soil moisture is determined by calculation. This method is based on theoretical and experimental dependencies by definition effective rain. Used to calculate the dependence takes into account water-physical properties of soil and rain options (Intensity, duration, etc.). The source parameter of the technological process of watering, characterizing the soil conditions, moisture content is calculated soil layer. According to the description of the author of the cashier's moisture layer of soil corresponding to $100 \%$ of the HB is determined from the expression [5]:

$$
(\mathrm{h})_{\mathrm{NV}}=100 \eta \mathrm{n} \beta \mathrm{HB}
$$

Where, $\eta$-volumetric mass estimated soil layer, g/cm3; $\mathrm{n}$-depth of the active soil layer, $\mathrm{m} ; \beta$-soil moisture percentage by weight of dry soil; If you consider that for heavy soil loamy humidity lower limit $\beta \mathrm{min}=80 \%$ of $\mathrm{NV}$ and an upper bound $\beta_{\mathrm{m} \text { oh }}=100 \% \mathrm{HB}$, for these conditions is the optimal soil moisture will be determined by the following formula [6]:

$$
\beta_{\mathrm{opt}}=\frac{\beta_{\max } \beta_{\min }}{2}
$$

that is, for heavy soil loamy optimum humidity $90 \%$ would equal a NV., Then the moisture content calculated soil suitable optimum humidity $\beta_{\text {wholesale }}=90 \% \mathrm{NV}$ will receive the following [7]:

$$
\text { (h) } \text { wholesale }=0.9(\mathrm{~h})_{\mathrm{NV}}
$$

T Akim of the same method, you can determine the optimal moisture content calculated soil for other soil conditions (light, medium, etc). Irrigation technology under drip irrigation should be carried out as follows. At the beginning of the vegetation period determine the initial humidity $\beta$ and the appropriate moisture content (h) 0 within the limits of the soil, while soil moisture is measured one of exact methods.
If it turns out that $(\mathrm{h}) 0<(\mathrm{h})$ wholesale, you must before the start of the growing period irrigation preirrigation irrigation norm of conduct [8]:

$$
(\mathrm{m})=(\mathrm{K}) \text { PL. }\left(\mathrm{h}_{\mathrm{opt}^{-}}-(\mathrm{h})_{0}\right)
$$

If $(\mathrm{h})_{0}>(\mathrm{h})_{\mathrm{opt}}$, the DSA vegetation glazes spend as many days later, while soil moisture reserves become (h) 0 descended to the level of $(\mathrm{h})_{\text {wholesale }}$. As usual vegetation watering (daily rate and duration of watering) on indicators of evapotranspiration. For this purpose use the SGI isparograf-3000. If the previous day evaporated from the soil, e.g. $5 \mathrm{~mm}$ of moisture, then during the day under drip irrigation of the soil served $2.5 \mathrm{~mm}$ (i.e. $25 \mathrm{~m} 3 / \mathrm{HA}$ ) moisture. Pass or other ways of irrigation (sprinkling) $5 \mathrm{~mm}$ (or $50 \mathrm{~m}_{3} / \mathrm{HA}$ ). This is because under drip irrigation is not all selhozkulturoj area is irrigated. Irrigated here locally only equal plots the root system of plants. Duration of work is defined in nomogram 3.4. In the bezdozhdlivyj period, this procedure is repeated every day. When rainfall, two or three days after rain measured soil moisture.

On the assumption that what is the difference between the $(\mathrm{h})_{0}$ and $(\mathrm{h})_{\text {opt }}$ or the soil paid one-time irrigation norm $(\mathrm{h})_{\text {wholesale }}-(\mathrm{h})$ $0\left(h_{\mathrm{opt}}>\mathrm{h}_{0}\right)$ or until the next watering the vegetation should wait for as many days as long as the soil evaporates difference, IE; (h) 0 - (h) opt. $\left(\mathrm{h}_{0}>\mathrm{H}_{\mathrm{opt}^{*}}\right)$. Measurement of evapotranspiration and daily watering duration are entered into a special register. Process parameters of irrigation are determined by accordance with nomograms.

These monograms are designed for heavy loam soils. Slope is assumed to be zero. When constructing irrigation standards definition nomographs for « $(\mathrm{m})$ «coefficient of moisture of soil equal 1 was adopted. This extends the scope of the monograms and other irrigation methods. It should be noted that under drip irrigation watering norms nomogram received correct value of coefficient of soil moisture, i.e.

$$
(\mathrm{m}) /=(\mathrm{k})_{\mathrm{PL}} *(\mathrm{~m})
$$

Nomographs on rice. Let polivalshhiku without making the soil moisture measurements to determine the parameters of technological process of irrigation. For reliable determination of technological process of watering us address some specific cases, it is rainy and bezdozhdlivyj periods. In the bezdozhdlivyj period irrigations are held as follows:

i. When carrying out growing period irrigation irrigation standards equal to the sum of evaporation over the previous 24 hours $e_{\text {exec }}$ soil moisture factor.

ii. Coefficient of moisture of soil with sprinkler amounts to $\mathrm{PL}_{\mathrm{PL}}$. $=1$, under drip irrigation to $\mathrm{PL}_{\mathrm{P}^{\circ}}=0.4$ i.e. drip irrigation is not the entire area is wetted.

Thus, when daily irrigation norm sprinkling equal $(\mathrm{m})=\mathrm{E}-\mathrm{flow}$, under drip irrigation $(\mathrm{m})=0.4(\mathrm{e})$ Spanish. 


\section{Global Journal of Otolaryngology}

In sprinkler irrigation technological parameters calculation period is as follows: using the GGI-3000 is determined by the amount of precipitation, evaporation over the previous 24 hours eexec, and duration of td rain using humidity recorder or air temperature (start and end of the rain on the Ribbon). Knowing the amount of precipitation (h) and duration of rain td you can easily determine the average intensity of rain [9]:

$$
i_{c p . u x m}=\frac{h}{T_{\not}}(12)
$$

Famous $t_{d}$ and (h) using equation (3.56) you can build nomogrammu the intensity of the rain.

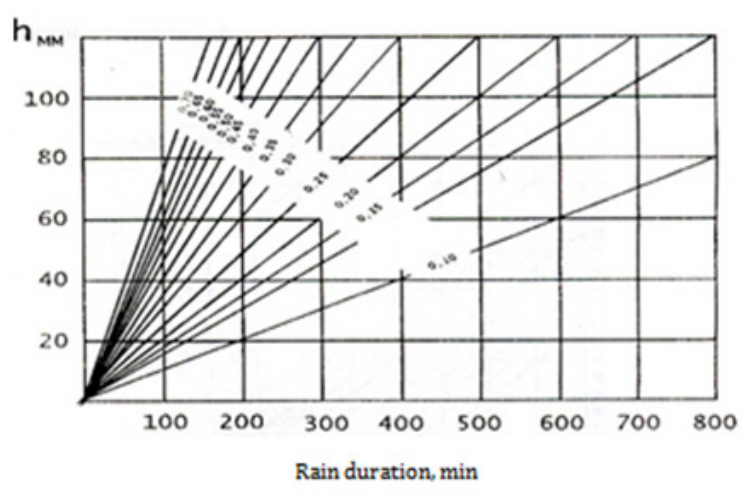

Figure 2: Nomogram for determining the intensity of rain.

The Figure 2 shows nomographs for determination of rain. $\mathrm{T}$ known $_{d}$ intensity (i) ${ }_{\text {int }}$ rain on the nomogram Figure 3 determine rainfall utilization to further using nomogrammu Figure 4 on known values of $\mathrm{k}, \mathrm{e}_{\text {exec }}$ and (h) to the desired watering rule comes to bring the soil moisture to an optimal level. Usually when rains current value was in the soil becomes more than you need, since rain soil humidity is maintained at an optimum level. The challenge is determining the current value of the accessibility of the soil after rain. While monograms on determining the intensity of rain build according to the duration of the rain against the number of atmospheric sludge. $\mathrm{Cm}$ (Figure 2). While rain increases by the value soil moisture reserves become layer effectively precipitation. Regular watering the vegetation after evaporation from soil effective rainfall. Thus, the proposed ways to define process parameters of irrigation, allow their use in the practical maximum productive use of fallen precipitation.

For this purpose it is enough to determine the required irrigation norm and assign the required dates and duration of the system (Figures $3 \& 4$ ). The results of the above calculation and performance claims that irrigation technology mikrodozhdevalnoj (MDK) as costs and agromeliorativnym indicators more effectively, and investment payback period is 3.0 years-quite normal rates. So-so small droplet size and rain intensity, uniform distribution of water for irrigation data square designs rain the irrigation system, ensuring good absorbency and ecological safety on any soils and slopes. Therefore, to assess the new micro-irrigation techniques developed by us it is advisable to compare their specifications.

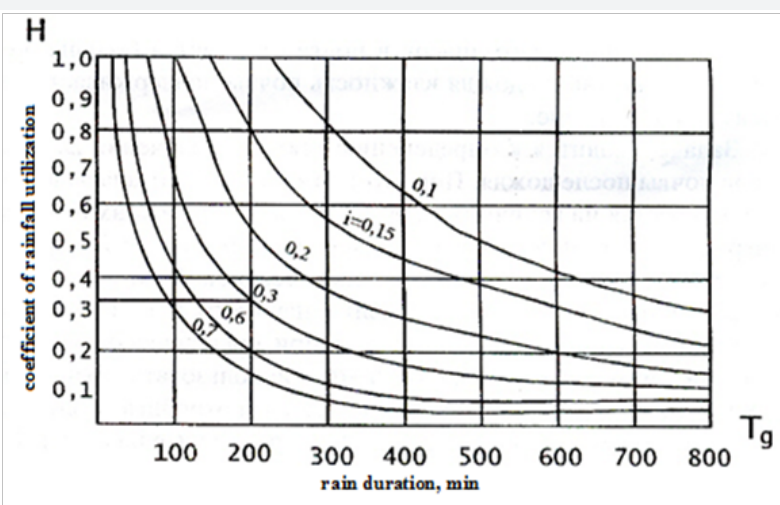

Figure 3: Nomogram for determining utilization rate of rainfall. Coefficient of rainfall utilization. Precipitation $\mathrm{mm}$

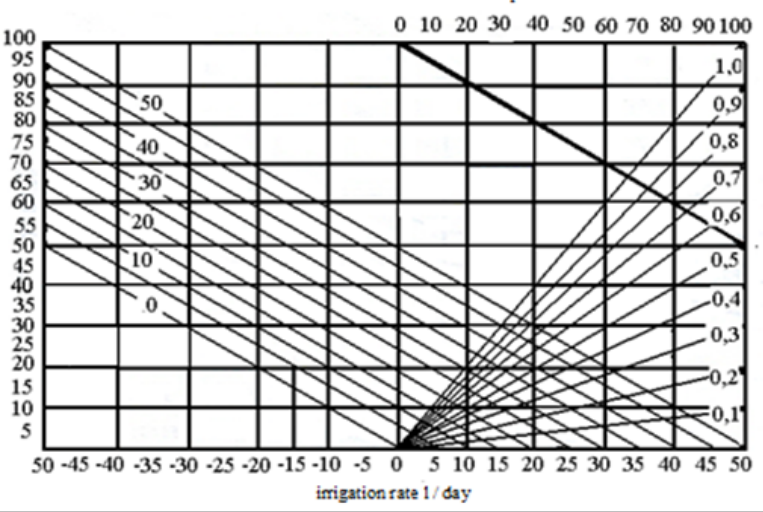

Figure 4: Nomogram for determining irrigation norms.

From the table it can be seen that by the number of vehicles on 1 hectare, i.e. reach capital investments when the identity of the other options, and much more economical KTMD IDAD model MDK. And systems mikrodozhdevanija model DMD for capital investment in 1.6 times cheaper base. In addition to these can also be noted that the application of the proposed mikrodozhdevanija system allows 1.6 times more economical or more spend irrigation norm compared with the base case. Therefore stimulates the activity of mikrodozhdevanie systems of physiological processes by creating the best water and nutrient regimes for crops: grapes, Apple, pear, sugar beets, soybeans and many others cultivated in conditions mountain agriculture.

Example calculations determine the economic feasibility of the use of the soya technology with mikrodozhdevaniem proves that in the cultivation of this culture with the introduction of macro and microelements is thrown with mikrodozhdevanija compared to the traditional option of irrigation (sulcus or puffed) annual economic effect is 5.496 thous. Manat with 1 hectare square. When this investment pays off for 3.0 years. With regard to the relatively low yield variants, it is a mismatch of natural conditions in the usual-by Frost, during shoots and weed research in these regions.

In addition, with the use of these systems of irrigation, watering can be performed in different ways, comfortable to the user: for 
example, in motion, position, when not required watering large areas; usually out of range of sprinkler apparatus driven by the rotation of the reactive force of flowing water under pressure, rotates through shut-off body with vodopodvodjashhim valve inside which creates a working pressure of throwing the Jet ejection water in the form of rain morosajushhego. Operating costs of these systems are insignificant, dozhdevatel is easily transported manually to another position, and not system network combined capital-intensive that advantageously differs it from foreign and domestic designs used for the last time.

\section{References}

1. BH Aliev, Aliev ZH (2001) Zoning of the territory of Azerbaijan Republic on choosing advanced irrigation techniques. Monograph, Publishing house "Ziya", Baku pp. 297.

2. BH Aliev, Aliev ZH (2003) Irrigated agriculture in the mountain and foothill regions of Azerbaijan. Monograph Publishing house "Naji Zia EPG Ltd" Baku pp. 330.

3. Aliev BH, Aliev ZH (1999) Techniques and technology few intensive irrigations in condition of the mountain region of Azerbaijan Publishers «Elm», Baku pp. 220.
4. Aliev ZH (2007) The premises about the most important problem of the agriculture in water resource provision mountain and foothill regions of Azerbaijan. J AAS, Baku pp. 179-182.

5. Aliev ZH (1999) The premises of the decision of the problems moisture provides agriculture cultures production in mountain and foothill region of Azerbaijan. The works of SRI «Erosions and Irrigations. Baku pp. 125-129.

6. (2002) International Center $C / X$ Research in the dry in the Dry Areas (ICARDA) Irrigation regime and monitoring equipment. In: U Umarova and A Karimov (Eds.), Taraz: IC "AQUA" pp. 128.

7. Rub Nosenko (1981) Irrigation in the mountains. Publishing House "Kolos", Moscow pp. 143.

8. Zakir Aliev (2005) Question to protect soil in Azerbaijan republic husbandries. Journal of water and land development, the Institute for Land Reclamation and Environmental Engineering in Agriculture, Polish academy of Sciences pp. 116-121.

9. Aliev ZG, Jafarov AM (2007) Use of the method of the Dynamic Programming in process of optimization of the irrigation agroculture in condition of mountain agroculture. Ninth International Congress Of Baku Energu, Egologu, Ekonomy Baku, Azerbaycan Respublik p. 7-9.

\section{Your next submission with Juniper Publishers will reach you the below assets}

- Quality Editorial service

- Swift Peer Review

- Reprints availability

- E-prints Service

- Manuscript Podcast for convenient understanding

- Global attainment for your research

- Manuscript accessibility in different formats ( Pdf, E-pub, Full Text, Audio)

- Unceasing customer service

Track the below URL for one-step submission https://juniperpublishers.com/online-submission.php 